\title{
Erratum to: Soy protein prevents renal damage in a fructose-induced model of metabolic syndrome via inhibition of $\mathrm{NF}-\mathrm{kB}$ in male rats
}

Nallasamy Palanisamy •

Carani Venkataraman Anuradha

Published online: 19 January 2013

(C) IPNA 2013

Erratum to: Pediatr Nephrol

DOI 10.1007/s00467-011-1882-1

The core data and conclusions were published before in another journal: Eur J Pharmacol (2011 Sep 30; 667:355$64)$. There is considerable overlap in the main sections.

The online version of the original article can be found at http:// dx.doi.org/10.1007/s00467-011-1882-1.

N. Palanisamy $(\bowtie) \cdot C$. Venkataraman Anuradha Department of Biochemistry and Biotechnology, Faculty of Science, Annamalai University,

Annamalai Nagar,

608 002, Tamil Nadu, India

e-mail: nalpybiochem@gmail.com 